\title{
Rethinking Turning Points: Trajectories of Parenthood and Desistance
}

\section{Marguerite Schinkel ${ }^{1}$}

Received: 18 January 2019 / Revised: 24 June 2019 / Accepted: 26 June 2019 / Published online: 30 July 2019

(C) The Author(s) 2019

\section{Abstract}

Purpose While much research has examined the role of parenthood in desistance, it has largely treated parenthood as a binary condition. This article examines the interaction between trajectories of parenthood and trajectories of desistance in order to understand how these interact over time.

Methods This article is based on life story interviews with 29 men and women in Scotland who had experienced repeated short-term imprisonment and mentioned children as significant in their lives, ten of whom were interviewed again 2 years later.

Results While becoming pregnant was a (very) positive turning point for many of the women, trauma surrounding parenthood through pregnancy loss, lack of conception and losing the parental role had a clear negative effect on trajectories of desistance.Men had similar experiences, although pregnancy was only a turning point for them if they felt their partner was not fulfilling their role as mother-to-be.

Conclusion A more nuance understanding of the lives of people processed by the criminal justice system is needed, looking beyond their interactions with the criminal justice system and not only in relation to parenthood but also with regard to other frequently cited 'turning points' such as work and relationships.

Keywords Parenthood $\cdot$ Desistance $\cdot$ Trauma $\cdot$ Drugs $\cdot$ Lived experience $\cdot$ Meaning of sentence

\section{Introduction}

The study of turning points in desistance has tried to identify events, experiences or social institutions that facilitate desistance $[29,35,42,52]$. By examining one such

Marguerite Schinkel

Marguerite.schinkel@glasgow.ac.uk

1 University of Glasgow, 63 Gibson Street, Glasgow G12 8LR, Scotland 
turning point, parenthood, this article will argue that the way in which turning points are often examined as binary conditions in quantitative research is misguided, and a misinterpretation of the literature from which 'turning points' emerged as a concept. There is a well-developed literature on the role of parenthood and desistance, examining how and under what circumstances having children makes a difference to offending behaviour ([1, 6, 14, 19, 21-23, 33, 36, 49]). In many of these quantitative studies, however, both offending and parenthood are treated as binary-you either have children or you do not; there are reductions in your offending or there are not, without much consideration given to the interaction of the trajectory of parenthood with the trajectory of offending. Even studies that acknowledge that parenthood cannot be examined as a binary condition and attempt to separate the effect of pregnancy from being a parent and include contextual factor measures such as the number of children and commitment to being a parent are still left with unclear results that the quantitative data cannot explain [1]. While many quantitative studies review the qualitative literature, they do not take seriously the idea that desistance is an individual journey [30] and therefore may be difficult to capture using aggregated data. This article argues that parenthood is a similarly individual experience for people with convictions, as it is for others. Problematising the focus in desistance research on turning points, this article examines how trajectories of parenthood can have different and changing meanings in relation to and beyond offending and desistance. Not only does much of the literature reduce parenthood to a binary condition, it also has the tendency to make parenthood and other 'turning points' subservient to desistance, only understanding it as a driver (or obstacle) towards this ultimate goal. While life-course criminology is inevitably interested in how different factors impact on offending, by examining different life events as factors in desistance it 'others' its research participants, for whom parenthood has many meanings beyond its impact on offending. Based on a study of the meaning of repeated short-term imprisonment in the lives of 37 participants, here the analysis focuses on the life stories of 28 men and women who spoke about parenthood in their interviews. It highlights that parenthood does not only affect identity and offending when first becoming a parent, but also through failing to conceive, pregnancies that do not end in a live birth, and the absence of living children. The significance of this article, then, is to ground the study of the link between parenthood and desistance in a more nuanced understanding of parenthood, while also problematising the way in which important life events in their own right are made subservient to desistance in the literature. More broadly, by using parenthood as an example, it shows how aspects of life which have been positioned as 'turning points' in the desistance and criminal careers literature are not 'points' at all, but complex processes incorporating a multitude of subjective meanings and experiences, with a number of effects on offending trajectories and beyond.

Significant interest has been paid to so-called turning points in the literature on desistance. When Sampson and Laub [42] first described marriage, employment and entering military service as turning points that could provide the impetus for desistance, they recognised that such changes did not affect everyone the same way. Military service, for example, provided some people with a new environment in which to be deviant, rather than facilitating change. They also described how the unravelling of initially positive turning points like marriage and employment could lead to a return to offending (p. 317) and did not only characterise turning points as one-off events, but 
also as 'processes of change over time' (p. 305). The main element missing from Sampson \& Laub's work was agency on the part of the desisting individuals, with Giordano et al. [19] arguing that employers taking a risk on people with a criminal record, even ones who had not yet made any effort to desist, was a product of the times of almost full employment. As [42]: 319), for later cohorts such external turning points were no longer readily available. Giordano et al. [19] instead developed the similar concept of 'hooks for change' (including parenthood) as opportunities to develop new identities for people who were already 'open to change'. Carlsson [8] problematized the idea of single turning points, arguing that the framing of a desistance pathway in this way by research participants is often the result of the interview questions asked. His participants instead spoke of a variety of factors interacting to motivate them to desist. While problematising the singular basis of turning points, Carlsson did not move away from the idea of a 'point' of change, even if this is produced by a multiplicity of factors, as he still focused on movements towards desistance. Maruna [25] also questioned the usefulness of the concept of turning points in desistance, instead preferring Lofland's 'disorienting episodes' (as cited in Maruna, [25], p. 25) to explain how experiences like hitting rock bottom might make some people turn away from crime, while others will turn towards it. Despite these nuances discussed in the literature on turning points and their alternatives, the desistance literature on turning points and hooks for change nevertheless focuses on on-off conditions and how they might facilitate desistance (see below). By focusing on one often cited turning point, parenthood, this article examines how we might conceptualise 'turning points' as trajectories, ${ }^{1}$ with changes in the meaning and experiences of parenthood over time connected to both positive and negative changes in offending behaviour.

Similar to the inconsistent findings in relation to employment and relationships [4, 40], large-scale surveys examining the effects of parenthood have produced inconsistent findings on whether having children leads to a reduction in offending $[6,40]$ or drug use [51]. Qualitative studies examining the experience of motherhood for women who are involved in crime and/or drug use [13, 48, 50] can explain some of the discrepancies in the quantitative findings. Being a parent provides people who offend with a new possible identity and a new routine, but parenthood is stressful, especially in the difficult circumstances in which many of the participants in these research studies lived, and therefore can also contribute to further substance misuse and offending $[2,7$, $32,48]$. For some, finding accommodation and sorting out finances post-prison takes so much effort and time that it takes precedence over reunification with children [32]. In addition, while many new parents struggle, drug using parents' difficulties tend to be viewed as 'of their own making', and they are therefore less likely to receive support than other struggling parents ([3], p. 512). While motherhood is usually recognised as a pro-social identity, research has also shown that it can be extremely difficult for young mothers who have offended in the past to overcome the label of offender as their master status [48]. Some authors have argued that motherhood only solidifies desistance, keeping mothers away from crime and drug use once they have started to desist, rather than initiating a move away from crime [2]. However, such studies tend not to differentiate between different stages of parenthood, which might impact on desistance

\footnotetext{
${ }^{1}$ Using the term also used by Sampson \& Laub (1993), who described turning points as changing life-course trajectories of offending.
} 
differently. With the focus in most studies on the parenting experiences of mothers, fatherhood trajectories have been relatively neglected [20], given that fatherhood can also offer a much-needed positive identity to offending men [31] and the common finding that parenthood has different impacts for men and women [1, 20,35]. While the pregnancy of their partner tends to have little impact on men's offending, the impact of fatherhood is mediated by the father's involvement and commitment to being a parent, opportunities for employment and the age when they first became a father, with teenage fathers more likely to persist $[16,35]$. This article explicitly considers the impact of the trajectory of fatherhood and how this differed from the trajectory of motherhood. For reasons of space, the overview of the literature on parenthood and desistance has been brief in this introduction, but further literature is threaded throughout the findings section.

As this research was conducted in Scotland, it is useful to briefly consider this context and how it might have impacted on the results. Scotland is a small jurisdiction, with a population of just under 5.5 million. Despite being closest in population to countries like Ireland, Finland and Denmark, its use of imprisonment is very closely linked to that of England and Wales, with an imprisonment rate of 148 per 100,000 (World Prison Brief). It has recently started to rise again, after falling to 140 in 2018 (ibid.), despite sustained political will over the last decade to reduce the prison population [46, 47]. Around 8000 prisoners are held in 13 prisons, two of which are managed privately. Until recently, women were only held in one prison, HMP Cornton Vale near Stirling, but it is being closed after a recommendation by the Commission on Women Offenders [11] was accepted by the Scottish Government. Small, communityfacing units for women are to be built, but in the meantime (and at the time of both rounds of the research) women were held in originally male prisons around the country, often occupying one wing. As elsewhere, prisoners in Scotland disproportionally come from the most disadvantaged communities [21, 26]. The Commission on Women Offenders [11] found that most female prisoners have complex needs, including experiences of abuse, mental health problems and addiction at levels that exceed those among male prisoners. While children of imprisoned fathers are often looked after by their mother, only $17 \%$ of children whose mothers are imprisoned live with their fathers [11]. This has consequences for the experiences described below, with none of the female participants having their children looked after by a partner, whereas this was common for male participants.

\section{Methodology}

This article is based on the Lives Sentenced research project, which examined the punishment careers of people in Scotland who had experienced multiple short-term prison sentences. While officially, in Scotland short-term sentences last up to 4 years, most sentences served by the participants were much shorter, usually less than 18 months. All participants had been to prison at least three times and experienced criminal justice punishments over at least 5 years. Through semi-structured life-history interviews conducted in 2014, I examined the perspectives of 22 men and 15 women on the meaning of this accumulation of punishment in their lives. They were asked to talk about their whole lives, being asked questions as 'what is your earliest memory?', 
'what do you remember most about elementary school?' and 'what have been the most important relationships in your life?'. Questions about their punishment careers included 'Tell me about your first sentence', 'Do any sentences stand out as particularly good/bad?' and 'What was (a particular) sentence like?'. Two years later, I reinterviewed the 11 men and six women who I was able to contact to see what had happened in their lives and how their perspectives had changed. Twenty-six of the original participants had children, and for three childless women being unable to conceive, an ectopic pregnancy or stillbirth had changed their lives. This article focuses on the accounts of these 29 participants, ten of whom were interviewed in both interview rounds, which means this article draws on 39 interviews, which lasted

Table 1 Participant characteristics

\begin{tabular}{|c|c|c|c|c|c|}
\hline $\begin{array}{l}\text { Pseudonym } \\
\text { and sex }\end{array}$ & $\begin{array}{l}\text { Age at 1st } \\
\text { interview }\end{array}$ & $\begin{array}{l}\text { Significance of children in } \\
\text { interview(s) }\end{array}$ & $\begin{array}{l}\text { Number of } \\
\text { children }\end{array}$ & $\begin{array}{l}\text { Location of } 1 \mathrm{st} \\
\text { interview }\end{array}$ & $\begin{array}{l}\text { Location of } 2 \text { nd } \\
\text { interview }\end{array}$ \\
\hline Alex (F) & $31-35$ & High & 0 & Prison & Prison \\
\hline Allan (M) & $26-30$ & Medium & 1 & Prison & - \\
\hline Andrea (F) & $31-35$ & Medium & 2 & Prison & - \\
\hline Angela (F) & $31-35$ & High & 0 & Community & Community \\
\hline $\operatorname{Baz}(\mathrm{M})$ & $36-40$ & Low & 1 & Prison & - \\
\hline Bill (M) & $31-35$ & High & 1 & Prison & Prison \\
\hline Brian (M) & $26-30$ & Medium & 2 & Prison & Prison \\
\hline Bruce (M) & $26-30$ & Medium & 1 & Prison & Prison \\
\hline Cairnie (M) & $31-35$ & Low & 2 & Prison & - \\
\hline Diana $(F)$ & $36-40$ & High & 1 & Prison & - \\
\hline Donna (F) & $36-40$ & Medium & 1 & Prison & Prison \\
\hline Eilidh (F) & $21-25$ & Medium & 1 & Prison & - \\
\hline Eve $(F)$ & $36-40$ & Medium & 2 & Prison & - \\
\hline Fagan (M) & $46-50$ & Low & 2 & Community & - \\
\hline Fred (M) & $56-60$ & Low & 2 & Community & - \\
\hline Jason (M) & $36-40$ & High & 1 & Prison & - \\
\hline Joseph & $41-45$ & Low & 3 & Community & - \\
\hline Marie (F) & $26-30$ & High & 1 & Community & - \\
\hline Michael (M) & $26-30$ & High & 1 & Prison & Community \\
\hline Michaela $(\mathrm{F})$ & $46-50$ & High & 0 & Community & - \\
\hline Parker (M) & $31-35$ & Medium & 1 & Community & Prison \\
\hline Peter (M) & $36-40$ & High & 3 & Prison & - \\
\hline Sally (F) & $31-35$ & High & 1 & Prison & Prison \\
\hline Savannah (F) & $41-45$ & Low & 2 & Prison & - \\
\hline Scott (M) & $31-35$ & High & 2 & Community & - \\
\hline Shelby (F) & $26-30$ & High & 1 & Prison & Prison \\
\hline Stuart (M) & $51-55$ & Medium & 1 & Community & - \\
\hline Suzie (F) & $31-35$ & Low & 1 & Prison & - \\
\hline Tyler (M) & $26-30$ & Low & 1 & Prison & - \\
\hline
\end{tabular}


between 40 minutes and over 2 hours. All the interviewees were White British, with almost all coming from disadvantaged backgrounds. For further details on the participants, see Table 1. The significance of children in their narrative was coded by the author as 'high' when interviewees dedicated lengthy portions of the interview to parenthood and linked it to desistance. It was rated as 'medium' when children were mentioned at some length during part of the interview or when their presence or absence was linked to offending behaviour. Where neither of these applied, but parenthood was mentioned (usually in passing), the significance was rated as 'low'. While most interviews were easily allocated to one category, there were some that another coder might have rated differently.

Imprisoned participants were recruited through Scottish Prison Service (SPS) staff, posters advertising the research in the prison hall and through snow-balling techniques (one participant inviting others to take part). Those in the community were recruited through third sector organisations and offered a $£ 10$ voucher for their contribution. All participants were provided with an information sheet about the research and given a chance to reflect on their involvement, after which several refused. Interviews lasted between half an hour and 2 hours, and were transcribed verbatim and subjected to both thematic and narrative analysis using NVivo 11. Coding was inductive and deductive, with themes from previous research and the literature informing some codes, such as 'rehabilitation' for perspectives on sentences. Others were based on the data alone, such as 'prison as aftermath', which meant it followed a more meaningful event, such as the loss of custody of children. As new themes emerged, previously analysed interviews were recoded for these. The interviews were also recrafted into a life story document, organised chronologically, which was shared with the participant. These were well-received; some participants said in the second interview that reading over their life story based on the first interview had given them a new perspective on their life.

The interview did not focus specifically on parenthood in any way; this means that the parts of the interview that related to children occurred spontaneously, and participants were free to put as much or as little emphasis on this aspect of their lives as they wished. The salience of children in the description of some life trajectories of crime and punishment is therefore not a result of the research focus. All names used in the findings below are pseudonyms chosen by the participants.

\section{Findings-Stages of Motherhood}

There is a very strong societal narrative on normal life progression, which includes parenthood [38]. This means that those who do not become parents can struggle with their view of themselves and their life's trajectory. Those who do become parents, especially women, are subject to another very strong cultural narrative - that of the good mother [27]. This revolves around selfless mothering, being fulfilled by the role and being a competent parent straight away, attuned to the baby's needs [10, 50]. Taking drugs and/or offending during pregnancy or beyond clearly does not conform to this narrative $[13,48]$. Not taking full responsibility for the care of children means a definite rupture with societal practice and convention [50]. 
There are very few studies that attend to the experience of unwanted childlessness, miscarriages or stillbirths in relation to offending. Most surveys only focus on those who are parents, i.e. those who have a living child, whether they take care of them on a daily basis or not. For example, Giordano et al. [20] categorised people as "(1) parent or (0) not a parent" (p. 408) in their quantitative analysis of the effects of parenthood, depending on whether a pregnancy had resulted in a live birth. This is a crude distinction and hides several states that other studies have shown can have great impact on how people see themselves and their life trajectories. This section of the article will chronologically progress through the different steps towards and through motherhood, and examine how these figured in participants' life stories, especially in relation to crime and punishment. It is followed by a section on the men's experiences of fatherhood.

\section{No Conception}

Infertility has been defined as not being able to conceive after a year or more of having regular unprotected sex [55]. This is the first step towards parenthood that figured in the research, central to one female participant's account of marital break-up, self-identity and offending. The lived experience of infertility and its diagnosis has been shown to be associated with depression, levels of distress similar to those experienced at being diagnosed with a life-limiting illness and post-traumatic stress disorder [12, 41, 45]. Describing her struggles with infertility, Michaela said ${ }^{2}$ :

I was 30-odds when I was told I couldnae have any children. I think that's been the worst time in ma life. And now as well, because I'm going through the change ae life, even though you've been told you cannae have kids,... when you go through the change of life, it's a definite. And I'm seeing a counsellor just now for that. It's like a death. It's that final, it's horrible, just horrible. I wouldn't wish that on anybody. ... [I was] 19 [when I got married], but it never lasted very long. He couldnae handle, he wanted children right away, after about 3 years, might have been 4 , he just left. But he met someone else, he's got a lovely wee boy now and it's hard wi; things like that, it's hard. Really hard. [If things had been different] I would never ever have been in prison again, wouldnae have took drugs, guaranteed. Mmmm. Because most of the drugs I took when I was younger was to block that out.

Involuntary childlessness could be described as a 'non-event' [45] and as such is hidden from commonly collected statistics, which perhaps explains why it has not been considered as a possible negative turning point within life-course criminology. Equally, if we only focus on the moment of diagnosis, we might miss that coping with infertility is a journey, with setbacks, such as losing a partner or menopause, along the way. Michaela's description of the on-going pain of her childlessness illustrates that this reverberated throughout her life. Research has also shown that the low self-esteem, depression, loneliness and sleep-problems resulting from infertility can last for decades

\footnotetext{
${ }^{2}$ In all quotes, the text between square brackets [] has been added in order to make sense of what is said, given that these are partial quotes, or to anonymise the quote'
} 
[54] and that the lack of parental identity can become the central focal point of women's life narratives. Life-long involuntary childlessness is relatively rare, affecting only 4 percent of couples in the USA (Abma \& Martinez, 2006, cited in [45], p. 213), so it is not surprising that only one of the participants was affected. It is worth examining Michaela's experience in this much depth, however, because of the lack of research on the link between infertility and offending. Michaela is unlikely to be alone; given the now well-established argument that infertility is a form of trauma [45], it is likely to compound other trauma in the lives of women who offend and they, like other women from low-income backgrounds, are less likely to seek and receive treatment, rendering eventual parenthood even less likely [5]. Since it has been shown that coping with involuntary childlessness is extremely difficult across socio-economic backgrounds [17], their turning to drugs or drink to cope, as described by Michaela, will not be uncommon, which might lead to (further) offending. Infertility deserves to be included in questions about the impact of parenthood on desistance in future research.

\section{Pregnancy}

While the lack of conception represents a gap in the life course criminology literature, ample work has investigated the impact of conception, especially in relation to drug abuse. Couvrette et al. [13] characterise this literature as producing inconsistent findings, with some studies showing that women often stop using drugs while pregnant, but others finding that only a minority does so. This might partly be due to a lack of nuance in conceptualising experiences of pregnancy. When the question of whether the pregnancy was wanted or not is considered at all, this is reduced to a yes or no question. For example, Giordano et al. [20] distinguish between those who wanted children when they got pregnant, those who did not or those who wanted children, but at some later point in the future. The last two were both considered 'unwanted pregnancies'. They found that parenthood was associated with the cessation of offending for more advantaged men and women, but only for less advantaged women when the pregnancy was wanted. However, this conceptualisation of the 'wantedness' of a pregnancy does not allow for the possibility of changing perspectives. In the Lives Sentenced research, six of the female participants had become pregnant by accident, and often not in the most settled of circumstances (while very young or in a very new relationship), but were nevertheless delighted by the prospect of becoming a mother. Some of this might be associated with the expectation, common amongst first time mothers [27], of a 'baby who never cries' and other unrealistically positive notions of motherhood ([13], p. 1261). Only two women described considering an abortion, both of whom nevertheless went on to have the baby, because of family pressure or being too far on in the pregnancy.

As discussed above, there is a very strong societal narrative around what it means to be a good mother-which seemed to have the effect of making pregnancy almost a 'structural' turning point [24] for the women who fell unexpectedly pregnant: one in which motivations to desist did not play an explicit role. As Giordano et al. [19] describe people obtaining work by default in the Glueck and Glueck research in the 1950 s, these women fell pregnant by accident. Almost none of them had intended to conceive, but as noted above and illustrated below, most of these women nevertheless described themselves as fully engrossed in the journey of pregnancy and parenthood 
from the very beginning. This, too, might be due to societal pressure in relation to impending motherhood, with negative feelings about pregnancy common, but often suppressed or left undisclosed [9, 27, 36]. On the other hand, the strength of the maternal narrative allowed these women to imagine an alternative self, one that was much more attractive than the 'feared self' involved in continued offending [34].

Five of the women had become pregnant before they became addicted to drugs or alcohol, and therefore did not describe efforts to change themselves or their behaviour during their pregnancy. However, those who suffered from addiction described themselves as determined to change their lives once they became pregnant.

She shouldnae even be here because that week, me and ma partner, we went on a total drug binge., ... they were telling me I was pregnant and [he was] coming back in, and I'm roaring and crying because I didnae think I would have kids, I'd never ever fell pregnant before. "What's the matter, are you dying or something?" "No, I'm fucking pregnant!" So that was it...that was me stopping everything, but they told me that I couldn't just come off the heroin because it would hurt her, and I had to go on methadone and I really didnae want to. (Diana, emphasis added)

While other research has considered methadone use to be continued drug use ([20] Giordano $[20,18]$ ), here the women were encouraged to start or continue taking methadone by medical professionals. While they complied, three said or implied they would have preferred complete abstinence. In this sense, the women were more ambitious and committed to tackling their drug habits to keep the foetus safe than the medical system allowed. Diana, quoted above, makes it clear that she only went on methadone because she was told to do so.

On top of tackling their drug issues, seven of the women were struggling with social services at the same time, meaning that they were under greater pressure to demonstrate their ability to be a 'good mother' than most.

Once I knew that I was [pregnant at] 7 month, I started getting a wee bump and that was a big turnaround in ma life at that point. I stopped using a lot of drugs, I was just on the methadone. I handed two clean urines in, social work was involved, they were saying I wasnae getting [child's name] when he was born because ae ma history and 'cos ae me being brought up, they were saying I hadnae been shown the right tools tae bring another baby up. So the end result was I had this wee baby and that was best thing ever. (Marie)

Marie's quote illustrates how such struggles with social services before the birth were usually overcome by the women interviewed for this project: none had had their child removed from their care immediately after birth. However, being known to social services and suspect as a mother, because of (past) drug use and not having been 'shown the right tools' often came back to haunt them later (see below).

\section{Pregnancy Loss and Stillbirth}

While the start of pregnancy was almost uniformly a positive turning point for those women who had drug or alcohol issues beforehand, the premature end of pregnancy 
was equally uniformly traumatic and a negative turning point in relation to offending behaviour, for the four women who experienced this and the two fathers whose partner lost a pregnancy who were expecting to be involved in their child's life.

Perhaps because of the hope engendered by pregnancy, losing a pregnancy was devastating. It is worth quoting one participant at length here, to show the emotional trajectory of being pregnant and then losing the pregnancy, even relatively early on.

I knew I was pregnant fae literally, I honestly think it was the following day. ...I remember sitting at the top ae the cliffs eating a Cornetto, and I remember saying tae ma friend "I think I'm pregnant, ma body just feels different". I went for a pregnancy test and I went tae the doctors, I was pregnant, they confirmed it. I was due for ma first scan, 4 or 5 days was it, before ma first scan, I was getting pains in ma stomach, it was like a popping sensation there in ma side. I thought I could feel the baby moving and I kept telling the doctor this and the doctor thought "daft wee lassie, she's just being a drama queen" and he was saying "the foetus is only the size of your thumb" and I was like "I don't care, I can feel it moving inside me" I was like "and it's sore." He was like "I know it's uncomfortable." He never sent me for any kind of check-ups or anything, just left it at that, just dismissed me and then I ended up waking up in ma bed, wi' blood fae up by ma belly button tae down by ma knees, just saturated in blood, and when I went up and went tae the toilet, it was like a bag ae like veins that fell away fae me, that's the only way I can describe it, and that's when I went tae the hospital. They told me it was an ectopic pregnancy that I'd had, the baby was stuck in the fallopian tube and the fallopian tube was twisted and stuck tae the inside wall of ma stomach. I couldae died, I didnae realise it, but aye, it was horrible. ...After I lost the wean, I hit it hard. I was taking [heroin] now and then, but when I found out I was pregnant I stopped taking it all together. But then I started tae think "Did I put too much stress on ma body? Is that maybe why this happened?" Starting tae blame maself in different ways but apparently the doctor said it was nothing [I did].... [The heroin]'s helped, it's really good tae block stuff out. It's a really good numbing effect that you get off it, but also it was the pain. It was definitely pain I was in, I was walking like I had a hump for like 12 weeks, because I couldnae straighten, because where this was stuck, when I straightened ma body, it stretched the tube. (Angela)

Angela's description of sitting on the cliffs eating ice cream is one of the only occasions in the interview where she painted a rosy picture of her life; one of ease, leisure and promise. Angela, like many of the other women interviewed, had not intended to conceive, but positioned herself as ready for motherhood. Her assertion that she 'literally knew from the following day' meant she was attuned to her baby even before the birth, and could be read as the prelude to a 'good mother' narrative [10]. Her interaction with the medical profession was less positive, mirroring the experiences of low-income and/or drug using women more broadly $[5,49]$. The doctor dismissed her as 'a daft wee lassie' despite her genuine concerns. Angela's open disagreement with the doctor intensifies her 'good mother' narrative, however brief. Her description of losing the pregnancy is 
difficult to read, let alone experience. However, this trauma did not stand alone for Angela, who was also in considerable pain for an extended period afterwards and not only felt grief at the loss of her pregnancy and future as a mother, but also guilt. While most women do not take heroin 'now and then', feelings of guilt after miscarriage are not uncommon given the emphasis in medical advice on proper pre-natal care and behaviour at the start of pregnancy [37]. For Angela, this pain and guilt meant 'she hit [drugs] hard', although here she does not explicitly make the link to her subsequent return to offending. Donna, who also had an ectopic pregnancy, did link this directly to further offending and imprisonment:

This year I fell pregnant. But I lost the baby. I had an ectopic pregnancy which was really quite bad, I had to get my tubes removed, one of them, my right hand side. When I fell pregnant we were so happy. Then that happened and my world, and his world, fell apart and I went on self-destruct and I've ended up back in here [prison] again.

The painful experience of pregnancy loss, and how this represents a trajectory of experience (through coping with the loss) more than a one-off event, is perhaps best reflected by one participant omitting her experience of her son's still birth from the first interview, which took place a few months after her loss. In the second interview, more than 2 years later, she still found it very difficult to talk about and worked hard to imbue the death of her child with some positive meaning. Initially, she resisted saying anything more than just that it had happened:

MS: You didn't tell me about the baby last time

Alex: No, I ken

MS: It must have been difficult for you, do you want to say anything more about it...

Alex: Yeah, (sighs)...no, no just now. Yeah.

Later in the interview, with her loss central to her experiences, she did return to it voluntarily, but with the repeated proviso that she would not say much:

I'm only going to say this wee bit right, but see when my waters broke, my mum and A came up to the hospital, and I was in labour for three days, and the baby died in his arms.

How current the grief still was for Alex more than 2 years afterwards is clear from her ongoing hesitation to name her baby. As she said:

Naming him I think is the last thing and I dinnae think I want to do it just. Yeah, that's it, I'm no wanting to talk about that anymore. I dinnae want to get you upset either.

Alex had lost her baby, but it is clear that she was not ready to let go of him, or herself as a mother. She wanted to delay her last act of motherhood; naming her 
baby. This description of such fleeting motherhood caught me unawares and brought tears to my eyes, as Alex graciously acknowledged, and she shut down the discussion of her son's birth and death once more. As the interview progressed, however, the death of her son formed a focal point for Alex in her intention to change her life, even though she recognised that her difficulty in dealing with his death had so far led to exacerbated drug use and offending, including the offence for which she was serving a sentence.

Obviously, I wish I would have had [the baby], but see at the end of the day, as much as it kills me, it's done good for me, because this is why I'm changing.

Alex was arguably trying to salvage something positive from her baby's death, and in this sense was unable to acknowledge the possibility that, had he lived, her baby's birth might also have inspired her to change. Alex was working hard to address her grief and her mental health problems during her sentence, but found it difficult to make progress as she was often moved between prisons and those helping her equally often changed position, so that she had to tell the same story, notably a story that she found difficult to tell, over and over again.

\section{Early Parenthood}

Ten of the women had living children and for three motherhood was especially significant in their life story and their trajectory of desistance. The length of time participants had full parental responsibility did not necessarily impact on how significant this was in their life story, which was more affected by how settled their children's situation was and how satisfied they were with the arrangements. For some who had only looked after their child for a few months, this represented the point in their life around which their story revolved, while others who had had their children for years did not dwell on this in the interview. The latter often had older children, who had lived with family members for years at the start of the interview, which meant their children's situation no longer was a cause for concern.

Despite evidence that early motherhood in particular can be a disappointing and distressing time for first-time mothers, given the gap between their experience and the expected 'ideal' of motherhood [10], Sally, Diana and Shelby described the time they cared for their children as the best time of their lives. As a single parent, Diana had managed to look after her daughter into her school years:

Up until she was about 4 or 5 . That was the best time ever. That was just, that was everything, do you know what I mean? It was just me and her, we were extra close. So that would be ma best time. (Diana)

These positive periods were not necessarily crime free, however. Diana still made money from dealing drugs on-and-off after the birth of her child, but by emphasising that her daughter was not affected by this she positioned it as a good solution to the tensions between single parenthood and the need to earn money (see also [39]) and resisted the idea that parents involved in drugs are by definition 'bad' parents (see also [13]). This had consequences for how she coped with losing custody (see below). 
Despite the findings in the desistance literature that parenthood can be stressful and thereby complicate desistance processes, the women who centred their life story around their children hardly ever acknowledged that single parenthood had been stressful for them. The challenges of parenthood only emerged in the accounts of those for whom motherhood was less significant (see for example Andrea's quote in the next section). Again, this might well be because the identity of 'good mother' was so important to them. Interestingly, men found it easier to acknowledge the stresses as well as the joys of parenthood (see below).

\section{Losing the Mothering Role}

Given that all the women were first interviewed in prison, it is a given that the positive turn of becoming a parent did not last for them. Ultimately, having the care of the child transferred to others was a negative turning point in the life narratives that centred around children. This removed the 'hook for change' that the child had represented and which had kept their mother in a positive place. Ten of the female participants described others taking over the care for their children. For the four women who had instigated this themselves, either by explicitly asking for help or as a consequence of escalating drugs use, losing care over the child was not experienced as traumatic in themselves. In these cases, children almost always went to their grandparents, other relatives or other trusted people known well to the participants.

D was on the heroin and then I think 'cos just pressure with him, he wouldn't come off the drugs and I think I just got to the point of if you cannae beat them, join them. I kindae liked the buzz ae them and it just took all ma problems away. Because I think I had post-natal depression, 'cos I didnae want ma wee lassie near me. As soon as she got older, she was like "Mum, mum, mum..." it was like too much, eh? I was like 'I'm just getting left wi' this baby, eh. He wanted her, I'm getting left. Where's he?" And then I got intae everything, it was just a total downward spiral fae there. (Andrea)

While losing the full-time parenting role was not traumatic, conceding being unable to cope as a parent was. Even when the participant felt that they had done the best thing for their children by giving them up, they still suffered, which often led to (increased) substance abuse and offending. For others, their children had stopped them from selfmedicating to deal with previous traumas. For example, Eve said:

One time I stayed clean for 9 months... that's when all the mental health [problems] kicked in. I went suicidal. Gave ma mum and dad the kids and...that was me. Then ma mum and dad had the kids so I just got oot ma nut. 24/7. Didnae want tae stay straight. I didnae want tae stop using. And it wasnae a case of just using heroin, I was shooting up everything.

This relapse or exacerbation of drug and/or alcohol use was closely connected to further periods of offending and imprisonment. The more traumatic way, in which custody of children could be lost was through forcible removal by social services or family, which six of the women experienced. For Diana, who resisted the 'bad parent' narrative, this was very traumatic. 
They busted ma house, didn't find anything except money and they said she was in danger, and that's when they put her to ma mum's and they would never recommend me getting her back. I stayed clean for about 6 months after that, and I went to them with clean samples, cos they never asked me for nothing. They didn't want me having her back, they made it quite clear. All I wanted was for them to say to keep going and they went, "No, we will not recommend, your house is too well known." I says, "Well, what if I move out of ma house? What if I get a job? What if I change my life totally and I'm clean for about 2 year?" and they went, "No." I went, "5 year?" and they went, "No. We'll never recommend it." They if they told me there was no hope, what was the point for me? There was no point, that was the only reason I stayed clean, was for her. I went "You know what, fuck the lot ae ye's." And that was when I went clean off the rails, I really started dealing quite badly and my door was going in every week, I was on the drugs all day, all night, didnae care. (Diana)

For Diana losing custody was the 'ultimate failure of identity verification' ([50], p. 967). Instead of being recognised as the good mother she felt she was, she was condemned as being unfit to look after her child, now or at any point in the future. As reported in other research [50], this led to a downward spiral, where Diana was 'on the drugs all day, all night' and did not care about the consequences, which included further repeated imprisonment after a hiatus of 8 years.

\section{Findings-Trajectories of Fatherhood}

Fifteen of the men interviewed had living children. For five, fatherhood was particularly significant in the life story they presented in the interview. Notably, for three of the five, their view that their child's mother fell short of being a 'good mother' played a significant part in their adopting the stance of 'good father'. While women started to aspire to being a 'good mother' as soon as they found out they were pregnant, for these men, the 'good father' role only became compelling once they perceived their partner as failing or having failed as mothers. For Jason, this meant that he tackled his own drug and drinking habits during his partner's pregnancy; not upon first finding out about it, but as a more deliberate reaction to the progressing pregnancy, presented as an agentic choice.

I knew she wasn't going tae be a good mother but, that said, I was going tae be a dad for the first time, so it was that bit ae excitement as well.... So as the months went by I was noticing her tummy getting larger and she starter showing, it was like "I need tae get ma act together, here, sober up". I was drinking and taking drugs, but 6 weeks before ma daughter arrived, I sobered up, because I knew [my partner] was on a prescription, she was taking drugs, she'd took drugs all her life and I thought if anyone's going to do it, between the two of us, it's going tae be me. I have tae get ma act together here, I want tae be a dad. I sobered up, I stopped drinking. I was still smoking a bit ae hash at night but never touched the drink, and I tried tae get ma head together. (Jason, emphasis added) 
The italicised part of the quote implies that Jason perceived himself as second in the line of responsibility, but felt he had to step up because he perceived his partner as unable to fulfil her role. Other research has also shown that men's drug dependency is usually unaffected during their partner's pregnancy [1].

Taking an active role as a father had meant that Jason desisted from substance use and offending for a relatively long period, while Scott was interviewed in the community and found looking after his children very supportive of his desistance.

R, it's because he's ma first and I've managed to be able to be there for him and bring him up, it's like I want tae give him ma all, focus on him and give him all ma time. He shouts 'Daddy' all the time. "Daddy! Daddy! Ta! Ta!" and that's helped a lot. That's helped a lot in ma life. I've had a lot ae hurt, a lot of pain and a lot of suffering in life. (Scott)

Giordano et al. [20] point out that children themselves cannot provide social control as they are helpless, at least at first. Scott's quote here shows that the bonding with a child can, however, change people's view of themselves and thereby heal emotional wounds. Having someone to care for and being loved by someone who needed him gave Scott a new lease on life. His desistance was threatened most severely by his adversarial relationship with the police (see Schinkel [44]). For Jason, a period of desistance from substance abuse and offending ended when he was no longer able to cope with the stress of being a single parent and gave the care of his daughter over to his mother. Afterwards, he was 'just consumed wi' guilt', and he dealt with his failure as a parent through escalating alcohol use, leading to homelessness and eventually reoffending. Not only had he failed in his own eyes, he had also lost his main source of support in the outside world. While his mother had always stood by him, when forced to choose between the welfare of her grandchild, who she was looking after fulltime, or Jason's, she chose the former:

Ma mum wouldnae even, if I phoned today, she would put the phone down on me. ...Ma mum's right. I mean, I'm just coming in and out of [my daughter's] life when I please. You know? .... And ma mum's only interested in HER well-being. You know, I've had ma chance [long pause] messed up. (Jason)

This further confirmed Jason's self-perception as a failure and also meant that his future desistance trajectory would be less well supported.

For Bill, the positive impact of being a father on desistance only ever existed in the future. During the first interview, he was very motivated to desist, so that he and his mum could gain custody of his son after he was taking into care because of his mother's drug use. Two years later, when he was interviewed again in prison and had not been able to secure custody of his son, this source of motivation no longer existed.

Peter was the only man interviewed who saw his partner as a 'good mother' and claimed the father role. When they had their first two children they were both desisting, but they lost custody and were imprisoned once they had returned to drug taking and dealing. Like Diana, he resisted the notion that either he or his wife had been bad parents. 
The lifestyle, what we were daen was wrong. But the kids wernae affected by it. Because at the time I was making a lot of money with ma work and selling drugs at the time, A. couldnae have been a better mother if she'd tried. We had the support of her family, ken roond aboot us all the time, I had great neighbours, so I had a great support network roond aboot us. But just because we took drugs as well, they made us sound like we werenae capable of keeping a cat. (Peter)

He had experienced losing custody of his children as far more stigmatising and punitive than the accumulation of prison sentences in his life:

Fair enough you do all these other things and you come tae jail and that, but to be told that you're not even fit enough to look after your ain kids, it's quite a...it's quite a hard thing, eh? (Peter, emphasis added).

For Peter, imprisonment pales in comparison to having children removed and placed in the care system, and illustrates the importance of interrogating the lived experience of such measures. Imprisonment is unlikely to have any kind of deterrent effect in this kind of situation, where it comes after an action by the state that is experienced as far more painful and traumatic. Like Diana, Peter was traumatised by losing custody:

It's took a long time to be able to speak about it, it's really horrible. It makes you feel like a total failure as a person erm, to no' have your own kids, to no' bring up your own kids. It's a horrible thing.

'Not having been able to speak about it for a long time' mirrors Alex's inability to speak about the stillbirth of her child discussed above and indicates the depth of pain around the loss of children, in whatever form, for men who value being a father as well as for women.

Finally, for Michael, it was pregnancy loss and then a subsequent pregnancy that interacted meaningfully with his trajectory of desistance:

She fell pregnant which was planned, but was'nae planned so quick. Then she got to 4 and a bit months, she had bloods taken, we found out she was going to have Down's Syndrome and possibly no' going to be able to walk either. We asked for an autopsy to be done when she came 'oot and she actually had a hole in her heart as well. So even if she did come into the world she was'nae going to be in the world very long. ...I went doon hill, I went right doon hill, I started taking drugs again, started binging, it was about a three month bender. I could'nae tell you a day within they three months. I was constantly 'oot of it. (Michael)

There is an element of defensiveness in Michael's emphasis that his daughter would not have lived long, even if he and his partner had gone against medical advice. This suggests that men as well as women feel the need to be recognised as a good parent even before the birth, scrutinising their own decisions [27]. Men have been found to react to pregnancy loss with less visible grief than women, feeling the need to be strong for their partner [28]. Due et al. [15] found that while men's experiences of distress and 
depression are less enduring than those for women after pregnancy loss, they are more likely to turn to alcohol as a way of coping. In this study, while Michael's 'three-month bender' might not be an unusual for a man in his position, if perhaps more extreme, it is also very similar to the reaction of 'going on self-destruct' (Donna) or 'hitting it hard' (Angela): in each of these cases the aftermath of pregnancy loss was one of (increased) drug or alcohol use and offending, which tended to be followed by further imprisonment.

\section{Data Sharing}

Data from the research has been deposited with the UK Data Service, SN 852680 and SN 852804.

\section{Discussion}

By examining one often cited turning point, namely parenthood, this article has emphasised the complexity of changes in people's lives and how such changes have meaning in and of themselves, as well as impacting on their desistance. Through examining in detail the participants' experiences of (not) being parents, the article has illuminated the ways in which not only the meaning of parenthood changes over time, but also what the term 'parenthood' actually represents in people's lives. While parenthood itself was sometimes found to be stressful, it was not having children that most often presented a negative turning point in life: not conceiving when you want to, losing a pregnancy and losing the care of a living child. Fewer men gave an account that revolved around (the absence of) their children, but when they either expected or saw themselves as having a significant role in their children's lives, the meaning of parenthood and the way this was perceived to interact with their offending trajectories and perceptions of punishment was similar to those of women. The exception found in this research was that (their partner's) pregnancy was not perceived as the same nearlystructural turning point for men, in which circumstances determine a change. Instead a partner's pregnancy could lead to a narrative of change through reflection and an agentic decision to take responsibility in a much more deliberative process.

As noted previously, the experiences reported here are heavily influenced by the research parameters. Recruiting people who have been sentenced repeatedly and interviewing most in prison makes it likely that they will have more experiences of negative turning points, including those related to parenthood. What is surprising for this group, though, was the way in which children often presented a positive turning point and the often significant periods of desistance that were associated with these. The small sample size and geographical location of the research mean that these findings cannot be generalised to other jurisdictions or the general population of parents with convictions, but it is likely their parenting trajectories are no less complex elsewhere, albeit potentially shaped by different factors and forces. Future research might want to examine the effect of different forms of child loss or absence (pregnancy loss, stillbirth, loss of custody, estrangement, the death of children) in relation to desistance trajectories in more detail. 
While the article focused exclusively on the 'turning point' or 'hook for change' of parenthood, other 'turning points' usually identified as being capable of bringing about desistance (such as employment and marriage) have similar features. Even well-paid and satisfying employment will not always and exclusively be experienced as positive, and will undergo changes over time (a new boss, bullying in the workplace, reorganisation, promotion) that have consequences for its meaning. Similarly, any marriage will have ups and downs (illness, the care of small children, infidelity by either partner, housework); even one with a 'pro-social' and supportive partner. Treating marriage, employment, and parenthood as binary conditions, and measuring their effect mainly through large-scale surveys, is to take a reductive view of the lives of people with convictions.

Importantly, even the lives of people who are persistently punished are not lived within the confines of the criminal justice system. This is where those who serve a long time in prison, but in instalments of short sentences, might be very different from those who serve long sentences in one block. Long-term prisoners often do make desistance a major long-term goal, one that can colour other aspects of their lives [43], but this is at least in part because any return to offending will have such serious consequences (i.e. an even longer or life sentence). Those who offend persistently are unlikely to face future (short) sentences with the same level of concern. The desistance literature so far has tended to focus exclusively on the desistance journey and how this is helped or hindered by criminal justice interventions. However, for many of those who are persistently punished and for whom punishment has therefore become normal, desistance will not be their most significant concern at any point, even though they might be desisting. They are not on a journey on their own, heading towards desistance and helped or hindered on that journey [30], or moving through different stages of desistance sequentially [22], but are instead negotiating heavy traffic, with desistance only a general direction that they are sometimes heading towards and sometimes not, depending on other desired destinations. Neither will they be most devastated by setbacks in their progress towards desistance; as this article has shown, setbacks and dead ends in their journey as parents will often be much more significant. Given their difficult circumstances 'avoiding crime can be the least of problems' ([53], p. 89). This is why it is important for desistance scholars to start to engage with the literature on the meaning and experiences of work, marriage, parenthood and other social institutions through which we all experience social life. While those who have been subject to criminal justice interventions are likely to be more vulnerable to setbacks than others (not least because these will be exacerbated by further criminal justice intervention), this should not mean that we ignore the aspects of their lives by which we organise our own. Only focusing on offending trajectories does not do justice to their experiences.

Acknowledgements I would like to thank the women and men who spoke with so much candour about both beautiful and difficult times in their lives. Thanks also to Dr. Caitlin Gormley, Dr. Andrew Smith, Professor Cyrus Tata and several anonymous reviewers for their insightful and supportive comments on earlier drafts of this article.

Funding This work was supported by the Economic and Social Research Council [ES/K009389/1].

Open Access This article is distributed under the terms of the Creative Commons Attribution 4.0 International License (http://creativecommons.org/licenses/by/4.0/), which permits unrestricted use, distribution, and reproduction in any medium, provided you give appropriate credit to the original author(s) and the source, provide a link to the Creative Commons license, and indicate if changes were made. 


\section{References}

1. Abell, L. (2018). Exploring the transition to parenthood as a pathway to desistance. Journal of Developmental and Life-Course Criminology, 4(4), 395-426.

2. Bachman, R., Kerrison, E. M., Paternoster, R., Smith, L., \& O’Connell, D. (2016). The complex relationship between motherhood and desistance. Women \& Criminal Justice, 26(3), 212-231.

3. Banwell, C., \& Bammer, G. (2006). Maternal habits: narratives of mothering, social position and drug use. International Journal of Drug Policy, 17(6), 504-513.

4. Beijers, J., Bijleveld, C., \& van Poppel, F. (2012). 'Man's best possession': period effects in the association between marriage and offending. European Journal of Criminology, 9(4), 425-441.

5. Bell, A. V. (2009). It's way out of my league: Low-income women's experiences of medicalized infertility. Gender and Society, 23(5), 688-709.

6. Blokland, A. A., \& Nieuwbeerta, P. (2005). The effects of life circumstances on longitudinal trajectories of offending. Criminology, 43(4), 1203-1240.

7. Brown, M., \& Bloom, B. (2009). Reentry and renegotiating motherhood: maternal identity and success on parole. Crime \& Delinquency, 55(2), 313-336.

8. Carlsson, C. (2012) Using 'turning points' to understand processes of change in offending: Notes from a Swedish study on life courses and crime, British Journal of Criminology, 52(1), 1-16.

9. Chew-Graham, C. A., Sharp, D., Chamberlain, E., Folkes, L., \& Turner, K. M. (2009). Disclosure of symptoms of postnatal despression, the perspectives of health professionals and women: a qualitative study. BMC Family Practice, 10, 7-16.

10. Choi, P., Henshaw, C., Baker, S., \& Tree, J. (2005). Supermum, superwife, supereverything: performing femininity in the transition to motherhood. Journal of Reproductive and Infant Psychology, 23(2), 167180.

11. Commission on Women Offenders (2012) Commission on Women Offenders. Retrieved on 15/3/15 https://www2.gov.scot/Topics/archive/reviews/commissiononwomenoffenders.

12. Corley-Newman, A. (2017). The Relationship Between Infertility, Infertility Treatment, Psychological Interventions, and Posttraumatic Stress Disorder. PhD Thesis, Walden University. Retrieved on 20/7/ 2017 http://scholarworks.waldenu.edu/dissertations/2805/

13. Couvrette, A., Brochu, S., \& Plourde, C. (2016). The "deviant good mother": Motherhood experiences of substance-using and lawbreaking women. Journal of Drug Issues, 46(4), 292-307.

14. Craig, J. M. (2015). The effects of marriage and parenthood on offending levels over time among juvenile offenders across race and ethnicity. Journal of Crime and Justice, 15(2), 163-182.

15. Due, C., Chiarolli, S., \& Riggs, D. W. (2017). The impact of pregnancy loss on men's health and wellbeing: a systematic review. BMC Pregnancy and Childbirth, 17, 380-393.

16. Edin, K., Nelson, T., \& Paranal, R. (2004). Fatherhood and incarceration as potential turning points in the criminal careers of unskilled men. In Patillo, M., Weiman, D. \& Western, B (Eds), Imprisoning America (pp 46-75). Russell Sage Foundation.

17. Forrest, L., \& Gilbert, M. S. (1992). Infertility: an unanticipated and prolonged life crisis. Journal of Mental Health Counseling, 14, 42-58.

18. Giordano, P. C. (2016). Mechanisms underlying the desistance process: reflections on 'a theory of cognitive transformation'. In J. Shapland, S. Farrall, \& A. Bottoms (Eds.), Global perspectives on desistance: Reviewing what we know and looking to the future (pp. 11-27). Abingdon: Routledge.

19. Giordano, P. C., Cernkovich, S. A., \& Rudolph, J. L. (2002). Gender, crime, and desistance: toward a theory of cognitive transformation. American Journal of Sociology, 107(4), 990-1064.

20. Giordano, P. C., Seffrin, P. M., Manning, W. D., \& Longmore, M. A. (2011). Parenthood and crime: the role of wantedness, relationships with partners, and ses. Journal of Criminal Justice, 39(5), 405-416.

21. Houchin, R. (2005) Social Exclusion and Imprisonment in Scotland - A Report, report to the Scottish Prison Service.

22. Healy, D. (2012). The dynamics of desistance: charting pathways through change. Cullompton: Willan.

23. Kreager, D. A., Matsueda, R. L., \& Erosheva, E. A. (2010). Motherhood and criminal desistance in disadvantaged neighborhoods. Criminology, 48(1), 221-257.

24. Laub, J. H., \& Sampson, R. J. (1993). Turning points in the life course: Why change matters to the study of crime. Criminology, 31(3), 301-325.

25. Maruna, S. (2001). Making good: How Ex-Convicts Reform and Rebuild their Lives. Washington, DC, US: American Psychological Association. 
26. Matthews, B. (2019). Is the relationship between imprisonment and deprivation in Scotland at its most pronounced in Glasgow? Howard League for Penal Reform ECAN Bulletin, 41, 51-58 Retrieved on 14/ 5/2019 https://howardleague.org/wp-content/uploads/2019/04/ECAN-bulletin-Spring-2019.pdf.

27. Mauthner, N. S. (2002). The darkest days of my life: stories of postpartum depression. Cambridge, MA: Harvard University Press.

28. McCreight, B. S. (2004). A grief ignored: narratives of pregnancy loss from a male perspective. Sociology of Health \& Illness, 26(3), 326-350.

29. McCuish, E., Lussier, P., \& Corrado, R. (2018). Incarceration as a turning point? The impact of custody experiences and identity change on community reentry. Journal of Developmental and Life-Course Criminology, 4(4), 427-448.

30. McNeill, F. (2016). The fuel in the tank or the hole in the boat? Can sanctions support desistance. In J. Shapland, S. Farrall, \& A. Bottoms (Eds.), Global perspectives on desistance: Rethinking what we know and looking to the future (pp. 265-281). Oxford: Routledge.

31. Meek, R. (2011). The possible selves of young fathers in prison. Journal of Adolescence, 34(5), 941-949.

32. Michalsen, V. (2011). Mothering as a life course transition: do women go straight for their children? Journal of Offender Rehabilitation, 50(6), 349-366.

33. Monsbakken, C. W., Lyngstad, T. H., \& Skardhamar, T. (2013). Crime and the transition to parenthood: the role of sex and relationship context. British Journal of Criminology, 53, 129-148.

34. Paternoster, R., \& Bushway, S. (2009). Desistance and the 'feared self': toward an identity theory of criminal desistance. Journal of Criminal Law \& Criminology, 99(4), 1103-1156.

35. Pyrooz, D. C., McGloin, J. M., \& Decker, S. H. (2017). Parenthood as a turning points in the life course for male and female gang members: a study of within-individual changes in gang membership and criminal behavior. Criminology, 55(4), 869-899.

36. Raymond, J. E. (2009). 'Creating a safety net': Women's experiences of antenatal depression and their identification of helpful community support and services during pregnancy. Midwifery, 25(1), 39-49.

37. Reinharz, S. (1988). What's missing in miscarriage? Journal of Community Psychology, 16(1), 84-103.

38. Reynolds, J., \& Taylor, S. (2005). Narrating singleness: life stories and deficit identities. Narrative Inquiry, 15(2), 197-215.

39. Robison, K. J., \& Hughes-Miller, M. H. (2016). Decentering motherhood: reentry strategies for women on parole and probation. Women \& Criminal Justice, 26, 319-339.

40. Rodermond, E., Kruttschnitt, C., Slotboom, A.-M., \& Bijleveld, C. C. (2015). Female desistance: a review of the literature. European Journal of Criminology, 1-26.

41. Rosner, M. (2012). Recovery from Traumatic Loss: A Study of Women Living without Children after Infertility. Thesis, Penn University.

42. Sampson, R. J., \& Laub, J. H. (2003). Life-course desisters? Trajectories of crime among delinquent boys followed to age 70. Criminology, 41(3), 555-592.

43. Schinkel, M. (2014). Being imprisoned: punishment, adaptation and desistance. Basingstoke: Palgrave MacMillan.

44. Schinkel, M., Atkinson, C., \& Anderson, S. (2018) 'Well-Kent faces': policing persistent offenders and the possibilities for desistance. British Journal of Criminology, 59(3), 634-652.

45. Schwerdtfeger, K. L., \& Shreffler, K. M. (2009). Trauma of pregnancy loss and infertility among mothers and involuntarily childless women in the United States. Journal of Loss and Trauma, 14(3), 211-227.

46. Scottish Government. (2017). Justice in Scotland: Vision and priorities. Edinburgh: Scottish Government Retrieved on 16/02/2018 https:/www.gov.scot/publications/justice-scotland-vision-priorities/.

47. Scottish Prisons Commission. (2008). Scotland's choice. Edinburgh: Scottish Government Retrieved on 6/11/2008 https://www2.gov.scot/Publications/2008/06/30162955/0.

48. Sharpe, G. (2015). Precarious identities: 'Young' motherhood, desistance and stigma. Criminology and Criminal Justice, 15(4), 407-422.

49. Stengel, C. (2014) The risk of being 'too honest': drug use, stigma and pregnancy, Health, Risk \& Society, 16(1), 36-50.

50. Stone, R. J. (2016). Desistance and identity repair: Redemption narratives as resistance to stigma. The British Journal of Criminology, 56(5), 956-975.

51. Thompson, M., \& Petrovic, M. (2009). Gendered transitions: Within-person changes in employment, family, and illicit drug use. Journal of Research in Crime and Delinquency, 46, 377-408.

52. Uggen, C. (2000). Work as a turning point in the life course of criminals: a duration model of age, employment, and recidivism. American Sociological Review, 65, 529-546.

53. Visher, C. A., \& Travis, J. (2003). Transitions from prison to community: Understanding individual pathways. Annual Review of Sociology, 29, 89-113. 
54. Wirtberg, I., Möller, A., Hogström, L., Tronstad, S.-E., \& Lalos, A. (2007). Life 20 years after unsuccessful infertility treatment. Human Reproduction, 22(2), 598-604.

55. World Health Organisation. (1992). Recent advances in medically assisted conception: Report of a WHO scientific group [meeting held in Geneva from 2 to 6 April 1990]. Geneva: World Health Organisation Retrieved on 21/3/2017 http://apps.who.int/iris/handle/10665/38679.

Publisher's Note Springer Nature remains neutral with regard to jurisdictional claims in published maps and institutional affiliations. 